\title{
Factors Determining Adoption of Outsourcing Logistics Functions: A Study of Manufacturing and Trading Sectors in Sri Lanka
}

\author{
C.Liyanagamage ${ }^{1}$, and R.Ranasinghe ${ }^{2}$ \\ ${ }^{1}$ Senior Lecturer, Faculty of Management Studies, The Open University of Sri Lanka, Sri Lanka \\ E-mail: hdcha@ou.ac.lk, rajith.ranasinghe@gmail.com
}

\begin{abstract}
This study aims at identifying the determinants of adoption of outsourcing logistic functions in Manufacturing and Trading companies in Sri Lanka. After careful review of the existing literature perceived cost effectiveness, quality concerns of logistics outsourcing, perceived risk and perceived professionalism of logistics service provider were identified for the study as their high theoretical and empirical importance in determining outsourcing decision. Primary data was collected by means of semi structured questionnaire from 60 organizations that carry out manufacturing and trading businesses in Sri Lanka. The collected data was analyzed using descriptive statistics and simple and multiple linear regression analysis. Initial simple linear regression analysis proved the statistically significant impact that each of the identified variables have on the adoption of outsourcing. However the multiple regression estimated in this study to analyze the collective effect of the suggested model concludes that the decision makers perception about the cost effectiveness of outsourcing and their perception of risk of outsourcing better explain the adoption of outsourcing in Manufacturing and trading sector in Sri Lanka. Hence, the outsource decision depends on the careful assessment of the decision-making company on its cost effectiveness and possible risk. Therefore, the findings of the present study suggest that outsourcing partners should be carefully selected in order to get the benefit of outsourcing.
\end{abstract}

Keywords: Adoption of Outsourcing, Logistics, Determinants of Outsourcing, Risk Of Outsourcing

\section{INTRODUCTION}

Competitive market environment and the globalization have immensely contributed to change the strategic directions of manufacturing and trading organizations in Sri Lanka. Many of these organizations have focused on their cost effectiveness and operational efficiencies in order to gain competitive advantages. The efficiency and effectiveness of the operations have considerable influenced not only on the operational performance of manufacturers and traders but also on the customer's perception of the quality of the products and services (Kenyon \& Meixell, 2010). In order to be successful in a competitive environment, organizations need to strategically focus on its key functions such as production, sales and logistics. These strategies also need to be matched with the capabilities of such organizations and the opportunities exist in the market place. The logistic operations among others are becoming increasingly complex for companies such as those in the manufacturing and trading sectors. Hence, companies are now realising the importance of logistics in their organisations and therefore the need for specialist input therein.Logistics is defined as a business planning framework for the management of material, service, information and capital flows. Furthermore, Logistics functions include transportation, distribution, warehousing, purchasing and import/export activities; most of which are considered as non-core business activities in an organization. However, logistics operations are vital for the effective supply chain management as it helps to reduce the cost and enhance efficiencies by improving organizational performance. Sri Lankan manufacturing and trading organizations have been facing numerous challenges due to constraints in logistics resources such as competent staff, advanced equipments, infrastructures, and other logistics related resources.

Unavailability of these resources in many organizations impacts on the performance of these organizations. This intern result in increase overall cost and decrease the efficiency of operational activities. Hence, these organizations tend to apply some strategies to overcome these issues therein. Outsourcing is one such strategy which considers obtaining specialist input for non-core business activities in the organization. Outsourcing logistics function is considered as transferring or delegating logistics activities such as transportation, distribution, warehousing, purchasing and import/export to a third party who is capable of operating all these activities on behalf of the organization. By doing so, the management of the organizations may anticipate a financial benefit, a superior customer service and benefits of using competent resources with a minimum risk.As per the literature, many organizations are very much interested in handing over some of non-core operations to another party who can provide a better service on behalf of the organization.

This is particularly true in the manufacturing and trading organization which has more non-core business activities such as IT, Distribution, warehousing and import/export etc. Kakabadse and Kakabadse (2000) state that there are three major categories of motivatiors for outsourcing: cost, strategy, and politics. The private sector is commonly driven by the first two motivators in outsourcing where as the public sector organizations are often driven by Political agendas in outsourcing. According to Jain \& Natarajan (2011), attitude towards outsourcing is positively influenced by the perceived benefits and perceived criticality of outsourcing; and negatively influenced by the perceived 
risks mitigation and perceived roadblocks for implementing outsourcing. However as Park \& Jeong (2016) say, it is not conclusive to rule out if it is right or wrong to outsource any work. Rather, the individual organization should carefully evaluate the pros and cons prior to make these vital decisions. Accordingly, making own decision through logical, sensible, and proactive base, through better negotiations, careful analysis and going for partnerships may be the key areas which need to be addressed (Park \& Jeong, 2016). Hence the adoption of outsourcing logistics and its drivers can be considerably differ from one industry to another and perhaps one organization to another within the same industry. The present study is an attempt to understand this reality in manufacturing and trading sectors in Sri Lanka.

\section{THE RESEARCH PROBLEM}

Manufacturing and trading industry in Sri Lanka is one of the main contributor of the economic development, and it represents more than 30 percent of Sri Lanka's entire economic growth. However, these two sectors have recorded some surprising downward growth for the past few years. Inflation has discouraged manufacturing firms in investing in new projects, as the higher cost of production squeezes the profit margin of the industry (Liyanagamage, 2009). Increased cost of materials due to high inflation and depreciation of the rupee has compelled the manufacturers and traders to minimize their operating cost and improve their efficiency to sustain with their businesses.

Those who could not adjust with these changes shutdown their businesses resulting a shrink in the industrial production growth rate from $10.3 \%$ in 2012 to 5.4\% in 2017 (CBSL, 2017) Outsourcing has been used by some organizations as a strategic management tool to build competitiveness, improve efficiency and productivity in their business operations. So, these organizations were encouraged to outsource all their logistics functions or only few selected functions such as warehousing and transportation. But not all the companies have outsourced their logistics functions, and even among those who outsourced, the degree of outsourcing is deferent from one to another.

Therefore, the main objective of the present study is to investigate empirically the determinants of outsourcing logistics functions in the manufacturing and trading sectors in Sri Lanka. In order to achieve this objective, the study is aiming at understanding first, the extent to which the manufacturing and trading sector companies adopt to outsource its logistics functions; second, examining the theoretically and practically important factors that influence on these outsourcing adoption; third exploring perceptions of manufacturing and trading companies on the importance of the identified factors, and finally, analysing the magnitude of the impacts of those identified factors on adoption of outsourcing logistic functions of manufacturing and trading companies in Sri Lanka.
The findings of the study will help the manufacturing and trading companies to sharpen their decision on outsourcing logistics functions while giving an insight to third party logistics companies (3PL) to improve their service levels, process \& procedures as per the perception of manufacturing and trading companies in Sri Lanka.

\section{LITERATURE REVIEW}

Every manufacturing and trading organization have core businesses and non-core businesses activities. The core business activities contribute directly to the industrial growth, hence these organizations need to be more focused on the core business activities. In order to do that, non-core business activities need to be overlooked and managed by another party. This means that giving non-core business activities to a capable service provider. Perhaps the most often cited strategic reason for outsourcing is to allow the organization to better focus on its core competencies (Sislian and Satir, 2000) Organizations can also offer a wider range of products and services at a faster rate than managing all operations in-house. This will enable manufacturing and trading companies to be more productive, efficient and effective.

Outsourcing advantages in many aspects including lowering operation cost, improving competitiveness, lowering capital investment, shifting resources to focus on core functions, generating demand for new growth and market segment, accessing world class capabilities, sharing risks and making capital funds available for core business investment. (Islam and Sobhani, 2008). According to the findings of Park and Jeong (2016), there are opportunities as well as threats of outsourcing that impact on the logistics operation management of an organization. Jain \& Natarajan (2011) state that the clients are becoming increasingly cautious regarding cost advantages.

Outsourcing decision can further be supported though the Resource-based theory, which says that competitive advantage of any organization is obtained through the analysis of all the internal resources available to that organization. The resource-based view (RBV) of an organization suggests that competitive advantages originate at the firm; specifically, that they derive from resources and capabilities of the firm (Teece, 1997). According to Amit and Schoemaker (1993), resources are assets that are either owned or controlled by a firm, whereas capabilities refer to a firm's ability to deploy resources to achieve a desired outcome.

The theory of core competences has been developed on the basis of the resource-based theory. Perunovic \& Lindgaard Pedersen (2007) defines that core competencies as the collective learning in the organization, especially how to coordinate diverse production skills and integrate multiple streams technologies. The application of concept of core competences in outsourcing became very popular among researchers. The concept has been predominantly used to 
develop and test various outsourcing decision frameworks arguing that the core activities shall remain in house. According to Lacity \& Willcocks, (2005).Vendor's competences are assumed to be one of the most important factors that influence success of an outsourcing arrangement.

Furthermore, the most utilized theory of outsourcing is Transaction Cost Economics (TCE) theory, which has been provided the best decision making tools to help organizations for deciding on outsourcing and preparing themselves for forthcoming outsourcing arrangements (Pedersen, 2007). The concept of switching costs made the theory applicable in the reconsideration phase. Another useful issue for outsourcing provided by TCE is explanation of contractual complexity. Though TCE has not been utilized explicitly for studying the Vendor selection phase, its sub-theory (if we may say so), the Theory of Incomplete Contracting, has been applied in studying the structure and contents of outsourcing contracts, and related preparation and contract management activities.

The Transaction Cost Theory (TCT) points out that, outsourcing decisions are influenced by the degree of asset specificity, frequency and uncertainty (Holcomb and Hitt, 2007) As per the study of Islam and Sobhani, (2008), overhead and fixed cost are the indicators measuring the extent to which outsourcing would help and has positive impact to reduce operating cost for example human resources, fixed assets and utility cost.

In most companies, outsourcing would help to reduce number of headcounts or employees whereby the core employees were shifted to focus on core functions. Thus, outsourcing would also reduce fixed asset quantity such as machinery and reduced the concern on depreciation value. Utility cost could also be reduced with less consumption.

And also Minondo \& Rubert, (2006) explained that exhausting the traditional modes of cost cutting such as staff rationalization and overheads reduction, outsourcing has become the most favored avenue for cost cutting with the idea being to outsource non-core business functions leaving the company to concentrate on its core objectives.

The function is outsourced when the in-house costs are higher than the anticipated costs for outsourcing the function. Therefore, the higher the internal cost to perform the function relative to the anticipated cost of outsourcing, the greater the probability of outsourcing (Bidwell, 2012).

Service quality of the third party is also indentified in the literature as another important aspect in outsourcing decision. Service quality can be defined as the conformance to customer requirements in the delivery of a service. Outsourcing will help to partner with service providers so they could handle specific business processes better, faster with their expertise which resulted to the customer satisfaction. Third party service providers can also contribute to improved customer satisfaction and provide access to international distribution networks. (Selviaridis \& Spring, 2007) The outsourcing organization may experience improved quality owing to focus upon their core business activities. Given that most of the external service providers excel at the services they provide; the outsourced services are guaranteed of better quality than would be provided in-house. Moreover, service providers will always seek to provide the best services since their reputation are at stake (Nicholas and Amrik, 2004).

When an organization is currently recognized for high quality, there may be concern by decision makers that outsourcing might affect the quality of services (Kremic, 2006). Among performance factors, service quality is the main subject which involves quality planning, quality assurance, quality performance, quality service level, quality improvement and benchmarking. Quality in the context of outsourcing is emphasized by Christin (2005) as a cause for concern by the client.

Despite the benefits that an organization can realize from its outsourcing, several studies however highlight the various risks the organization get exposed to while engaging in outsourcing. Company must manage several risks connected to the outsourcing in order to prevent severe damage. In order to outsource previously in-house activity results in need to dismiss or reassign employees. This will intern result in morale issues or even boycott from its employees (Windrum, 2009). Rouse \& Corbitt (2003) explain and subsequent studies support the argument that managing vendor relationship is another major risk associated with outsourcing, which if not managed properly, can potentially lead to poor realization of expected benefits and also damage the organization seriously.

The lack of methodology is believed to cause some outsourcing failures. This thought is supported by Lonsdale (2014) who suggests that outsourcing failures are not due to an inherent problem with outsourcing but rather the lack of guiding methodology for managers.

An alternative factor affecting for outsourcing decision is the competencies of the service provider who takes fully control of some functions of the organizations. One of the top ten reasons companies to outsource their functions is to gain access to the world class capability that will not be available in-house (Outsourcing Institute, 2006).

Service provider would usually have the best, the latest and high efficiency technology considering that the providers were specific in such service business function area. Ogorelc (2007) explains that to be successful in outsourcing logistics, the company should learn and consider how to select a logistics provider carefully. With the development of computer and information technology, it is useful for logistics providers to improve their performance and potentially save operations cost in the long run. 


\title{
IV. CONCEPTUAL FRAMEWORK AND THE METHODOLOGY
}

\author{
Independent variables Dependent variable
}

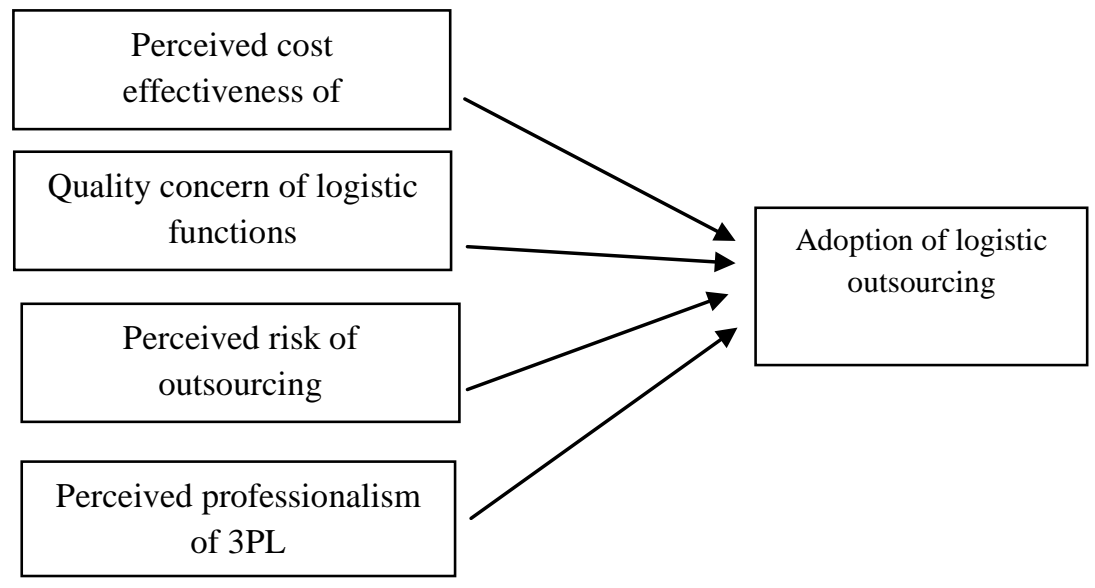

Fig. 1 Conceptual Framework

The logistics outsourcing decision can be considered as a variation of the classical make or buy decision (Harland, 2005). However, all the companies have not outsourced their logistics functions, and even among them, the degree of outsourcing is deferent from one to another. The action of choosing to take up, follow or use of the service of outsourcing is called as 'adoption of outsourcing' and is the dependent variable of the present study. The critical review of theoretical and empirical literature suggests some factors as drivers of adoption of logistics outsourcing. The cost effectiveness of outsourcing is an important determinant among them.

Logistics service providers can serve multiple customers and are able to utilize capacity better and spread out logistics costs, thus achieving economies of scale (Selviaridis \& Spring, 2007). Thus, the companies' assessment of overall cost effectiveness of outsourcing i.e. Perceived Cost Effectiveness is considered as one of the independent variable. Outsourcing will help to partner with service providers so they could handle specific business processes better, faster with their expertise which resulted to the customer satisfaction. Service providers will always seek to provide the best services since their reputation are at stake (Nicholas and Amrik, 2004). Hence the companies concern of overall service quality i.e. Quality Concern of logistic functions is considered as another independent variable. Perceived Professionalism also included in the conceptual model as it is one of the top ten reasons for companies to outsource their functions in order to gain access to the world class capability that will not be available in-house (Outsourcing Institute, 2006). Even though, decision on outsourcing is backed by the above three variables (cost effectiveness, quality concern of logistic functions and perceived professionalism of the service provider) risk factor (Perceived Risk of outsourcing) also need to be considered when transferring the business function to third party service provider.

\section{HYPOTHESES}

In order to understand the determinants of adoption of logistics outsourcing, following hypotheses were developed and tested in this Study.

$\mathrm{H} 1$ :The level of company's perception on cost effectiveness of logistics outsourcing, positively impact on the adoption of outsourcing.

H2: The level of company's concern on service quality of logistics functions, negatively impact on the adoption of outsourcing.

H3: The level of company's perception on risk of logistics outsourcing, negatively impact on the adoption of outsourcing.

H4:The level of company's perception on professionalism of third party logistics service provider, positively impact on the adoption of outsourcing.

\section{SAMPLE AND METHODOLOGY}

In this study, 60 numbers of manufacturing/trading organizations were selected as a sample by using convenience sampling method and all the organizations were selected from western province since there were $54.2 \%$ of manufacturing establishments were listed in the western province (Annual survey of industries, 2012). Data collection was based on a self-administered structured questionnaire with 5 questions for general information in section $\mathrm{A}$ and 23 questions in section $\mathrm{B}$ to cover dependent \& independent variables. Questionnaire was distributed among 60 organizations which are in the manufacturing/trading sector, out of which 58 respondents filled and returned the questionnaires making a response 
rate of $96.66 \%$. Data collected through the questionnaire was subjected to Cronbach's alpha reliability test to ensure that the instrument items were homogenous and reflected the same underlying constructs before the rest of data collection. Analysis of the data was done using the statistical package for Social Sciences (SPSS Version 20.0). Correlation analysis and regression analyses were used for testing hypotheses. The Cronbach's alpha values range from 0.746 to 0.829 concluding that data reliability and the internal consistency were within the standard parameters.

\section{FINDINGS AND DISCUSSION}

According to the data gathered from the questionnaire, $43 \%$ of the respondent companies are manufacturing \& trading businesses, another $29 \%$ of the companies are in manufacturing and balance $28 \%$ of the respondent companies are in trading businesses. And, 55\% of the respondents were in manager category and $45 \%$ of the respondents were in executive category implying that all response received from the companies are valid as they are in executive or manager category and are well aware of all related activities in the businesses.

\section{Types of Operation}

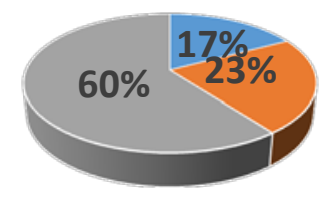

\section{- Own $=$ Outsource own \& outsource}

Fig.2 Methods of Operation

In the preliminary analysis of data it was found that, $60 \%$ of the respondent companies are managing their logistics activities by using both own and outsourced method and $23 \%$ of the respondent companies are managing their activities with the outsourced method and rest of the respondent companies (17\%) managing their business by own management implying outsourcing is the mostly used method of managing non-core business activities of manufacturing and trading companies in Sri Lanka.
Respondents were requested to indicate percentage of outsource in logistics activities to get an understanding of what percentage of activities are outsourced and depicts in Figure 3.

\section{Percentage of outsource}

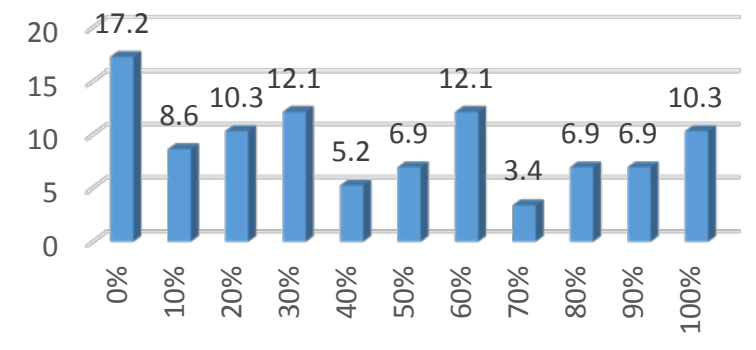

Fig. 3 Percentage of outsource

The highest percentage; i.e $17.2 \%$ of respondents have marked $0 \%$ outsourced. This means that, around $17 \%$ of the sample companies fully manage their logistics operations by themselves. Another $10.3 \%$ of companies have stated that they have $100 \%$ outsourced and the outsourced percentage of rest of the companies lay in between $10 \%$ and $90 \%$. These findings reveal that nearly 83\% of manufacturing and trading companies in Sri Lanka outsource their logistics operations at different levels. The mean value of percentage outsource was stood at $44 \%$ denoting moderate level of outsourcing (logistics operations) by Sri Lankan manufacturing and trading companies.

\section{DESCRIPTIVE ANALYSIS}

Descriptive statistics were analyzed to understand the perception of respondent companies on the variables selected in this study. The mean values of all the variables range between 3.36 and 3.89 denoting moderate levels of companies' satisfaction on cost effectiveness, quality concern of logistics functions, risk and trust on their logistics service provider. From among them trust on their logistics service provider was the most satisfied factor.

TABLE I DESCRIPTIVE STATISTICS

\begin{tabular}{|l|c|c|c|c|c|c|c|c|c|}
\hline & $\mathbf{N}$ & Min & Max & Mean & Std. Dev & \multicolumn{2}{|c|}{ Skewness } & \multicolumn{2}{|c|}{ Kurtosis } \\
\cline { 2 - 11 } & Statistic & Statistic & Statistic & Statistic & Statistic & Statistic & Std. Error & Statistic & Std. Error \\
\hline $\begin{array}{l}\text { Perceived cost effectiveness of } \\
\text { outsourcing }\end{array}$ & 58 & 2 & 5 & 3.64 & .757 & -.733 & .314 & -.066 & .618 \\
\hline $\begin{array}{l}\text { Quality concern of logistic } \\
\text { functions }\end{array}$ & 58 & 1 & 5 & 3.38 & .862 & -.268 & .314 & -.422 & .618 \\
\hline Perceived risk of outsourcing & 58 & 2 & 5 & 3.36 & .755 & -.128 & .314 & -.396 & .618 \\
\hline Perceived Professionalism of 3PL & 58 & 2 & 5 & 3.89 & .643 & -.774 & .314 & .530 & .618 \\
\hline Adoption of outsourcing Logistics & 58 & 1 & 5 & 3.42 & 1.057 & -.416 & .314 & -.213 & .618 \\
\hline
\end{tabular}




\section{HYPOTHESES TESTING}

Regression analysis is the tool to establish the strength and direction of the relationship between the independent variables and the dependent variable. And also, regression differs from correlation as it believes a causal relationship.
In this research study, simple linear regression analysis was carried out to identify the causal relationship between Adoption of Outsourcing Logistics functions (DV) and Perceived cost effectiveness, Quality concern of logistic functions, Perceived risk, Perceived professionalism of logistics service provider.

\section{TABLE II SUMMARY OF REGRESSION MODELS}

\begin{tabular}{|c|l|c|c|c|c|c|}
\hline Model & Variable & Constant & Coefficient & Adjusted R Square & F Stat & DW Stat \\
\hline 1 & Perceived cost effectiveness & 0.561 & $0.563^{* * *}$ & 0.305 & $5.97^{* * *}$ & 1.14 \\
\hline 2 & $\begin{array}{l}\text { Quality concern of logistics } \\
\text { functions }\end{array}$ & $1.375^{* *}$ & $-0.494^{* * *}$ & 0.230 & $18.03^{* * *}$ & 1.32 \\
\hline 3 & Perceived risk of outsourcing & 0.756 & $-0.566^{* * *}$ & 0.308 & $25.41^{* * *}$ & 1.48 \\
\hline 4 & $\begin{array}{l}\text { Perceived professionalism of } \\
\text { Logistics service provider. }\end{array}$ & 0.728 & $0.421^{* * *}$ & 0.162 & $12.04^{* * *}$ & 1.45 \\
\hline
\end{tabular}

a.,b.,c.,d., Predictors: (Constant), Perceived cost effectiveness, Quality concern of logistic functions, Perceived risk and Professionalism of Logistics service provider Dependent Variable: Adoption of outsourcing logistics functions***. Correlation is significant at the 0.01 level (2-tailed).

As per the results of the simple regression models performed, Perceived cost effectiveness, and Professionalism of logistics service provider found to have positive impact towards the adoption of outsourcing logistics functions, whereas Quality concern of logistic functions and Perceived risk revealed a negative impact on adoption of outsourcing logistics functions.

The correlation coefficient found in relation to perceived cost effectiveness is 0.563 and it was statistically significant at $99 \%$ level of confidence. This says that higher the companies belief of cost effectiveness of outsourcing, their adoption of outsourcing is higher. The strength of the found coefficient is at moderate level and hence it says if companies' perception on cost effectiveness of outsourcing increased by $100 \%$, then their adoption level will increase by $56 \%$. This finding could be true as cost effectiveness of outsourcing is well understood among many manufacturers/traders. Overhead and fixed cost reduction due to outsourcing would help to reduce operating cost of the manufacturing and trading; for example human resources, fixed assets and utility cost. Thus, outsourcing would also reduce fixed asset quantity such as machinery and reduced the concern on depreciation value.

Utility cost could also be reduced with less consumption. Desire to save indirect costs can be a major source of motivation to outsource. Having fewer employees requires less support system and infrastructure which gives organizations the opportunity to be more efficient. The findings of the present study reveal that outsourcing has become one of the most favored avenues for cost cutting among manufacturing and trading companies in Sri Lanka. As suggested by Bidwell (2012), the study confirms that lower the anticipated cost of outsourcing compared to perform them in-house, the greater the probability of outsourcing. Hence, Hypothesis 1 formulated in this study is accepted.
Perceived quality of logistic functions was found as a significant determinant that affect on adoption of outsourcing. Found coefficient was statistically significant at $99 \%$ level of confidence, but not very strong and stood at -0. 494. This statistic reveals that being other factors constant the companies are highly concern about the quality of logistics functions, then those companies' adoption to outsourcing is also lower. The findings of the study confirm the findings of Kremic (2006), when an organization is currently recognized for high quality, there may be concerns by decision makers that outsourcing might affect the quality of services. This reveal the decision makers fear about the service quality of 3PL compared to their own service quality. The fear of loosing customers due to drop in service quality will refrain decision makers from outsourcing their logistics functions. Thus, Hypothesis 2 of this study is accepted.

Hypothesis 3 of the study, i.e. “The level of company's perception on risk of logistics outsourcing, negatively impact on the adoption of outsourcing” could be accepted as the found coefficient is significant at 99\% level of significant. The coefficient is moderately strong and stood at -0.566 . This says, when the companies perceive that outsourcing logistics functions is a risk in all aspects, then their motivation to outsourcing will be low. This finding may be true as the companies will have to face employee issues arise with dismiss or reassign employees, managing vendor relationships and any other risks that companies would exposed due to outsourcing. Therefore, our study is consistent with Windrum, (2009) and Rouse \& Corbitt (2003).

Individual effect of perceived professionalism of logistics service provider was found as positive but below moderate level and was 0.421 . However, this effect is statistically significant at 99 percent level of significant. Therefore, Hypothesis 4 formulated in this study is accepted. This proves that perceived professionalism is one of the 
determinant that considered by decision makers to outsource their logistic functions. If the decision making company trusts on the professional capabilities of 3PL and their uninterrupted service their motivation to outsourcing will ne high. This finding proves the common wisdom and common expectation from a 3PL, i.e. possessing the best and latest technology and expertise in providing a better service than that was provided by the decision making company. Hence findings of the study agree Ogorelc (2007) and suggest the decision making company should learn and consider how to select a logistics provider carefully.in order to be successful in outsourcing logistics.

\section{SEARCHING FOR THE BEST MODEL}

Though all the hypotheses developed in study could be accepted, their impacts were analyzed taking only the decisive variable at a time and assuming other factors being constant.
However, practically decision/adoption of outsourcing is an outcome of careful analysis of many aspects as stipulated in the conceptual framework suggested in this study.This is particularly true as impact of one variable perhaps offset by another variable when someone is arriving at the final decision.

Hence the purpose of this section is to analyze the collective effect of identified variables on outsourcing adoption. For that, a multiple regression analysis was run taking Adoption of outsourcing as the dependent variable.

As we do not find strong correlations among independent variables there is no any evidence for exist of multicollinearity, hence all the identified independent variables were included in the multiple regression model. Table III summarizes results of the multiple regression analysis.

TABLE III RESULTS OF THE MULTIPLE REGRESSION ANALYSIS

COEFFICIENTS $^{\mathrm{a}}$

\begin{tabular}{|c|c|c|c|c|c|c|c|}
\hline \multirow{2}{*}{ Model } & \multicolumn{2}{|c|}{$\begin{array}{l}\text { Unstandardized } \\
\text { Coefficients }\end{array}$} & \multirow{2}{*}{$\begin{array}{c}\begin{array}{c}\text { Standardized } \\
\text { Coefficients }\end{array} \\
\text { Beta }\end{array}$} & \multirow{2}{*}{$\mathrm{T}$} & \multirow{2}{*}{ Sig. } & \multicolumn{2}{|c|}{ 95.0\% Confidence Interval for B } \\
\hline & B & Std. Error & & & & $\begin{array}{l}\text { Lower } \\
\text { Bound }\end{array}$ & Upper Bound \\
\hline (Constant) & -.254 & .724 & & -.351 & .727 & -1.707 & 1.199 \\
\hline $\begin{array}{l}\text { Perceived cost } \\
\text { effectiveness }\end{array}$ & .456 & .195 & .327 & 2.334 & .023 & .064 & .848 \\
\hline $\begin{array}{l}\text { Quality concern of } \\
\text { logistic functions }\end{array}$ & .073 & .190 & .060 & .384 & .703 & -.308 & .454 \\
\hline Perceived risk & .441 & .220 & .315 & -2.010 & .049 & .001 & .882 \\
\hline $\begin{array}{l}\text { Perceived } \\
\text { professionalism of } \\
\text { Logistics service } \\
\text { provider }\end{array}$ & .073 & .222 & .045 & .330 & .743 & -.373 & .520 \\
\hline $\begin{array}{l}\text { Adjusted R squa } \\
\text { DW Stat } \\
\text { F Stat }\end{array}$ & ed $\quad($ & $\begin{array}{l}37 \\
.32 \\
.23^{* * *}\end{array}$ & & & & & \\
\hline
\end{tabular}

At the initial estimation of the model, only perceived cost effectiveness and perceived risk found as significant determinants, whereas the significance of Quality concern of logistic functions and perceived professionalism of 3PL disappeared.

This can be due to the importance given to Cost effectiveness and risk factor out weight that of quality concern and professionalism at the point of decision making.

Therefore in order to find the best model that explains the outsourcing adoption of Sri Lankan Manufacturing and Trading sectors the regression model was re-estimated by
Eliminating one insignificant variables at a time until the model remains only the significant variables. Accordingly, Perceived professionalism of 3PL was first removed and then

Quality concern of logistics functions was removed as it remains insignificant even after the removal of fist variable.

The significance level of remaining variables were improves after removing the insignificant variables. The final estimation is presented in Table IV. 
TABLE IV RESULTS OF THE FINAL MODEL

\begin{tabular}{|c|c|c|c|c|c|c|c|}
\hline \multirow[t]{2}{*}{ Model } & \multicolumn{2}{|c|}{$\begin{array}{c}\text { Unstandardized } \\
\text { Coefficients }\end{array}$} & \multirow{2}{*}{$\begin{array}{c}\begin{array}{c}\text { Standardized } \\
\text { Coefficients }\end{array} \\
\text { Beta }\end{array}$} & \multirow[t]{2}{*}{$\mathrm{t}$} & \multirow[t]{2}{*}{ Sig. } & \multicolumn{2}{|c|}{ 95.0\% Confidence Interval for B } \\
\hline & $\mathrm{B}$ & Std.Error & & & & Lower Bound & Upper Bound \\
\hline (Constant) & $\begin{array}{r}- \\
.107\end{array}$ & .586 & & -.183 & .856 & -1.281 & 1.067 \\
\hline $\begin{array}{l}\text { Perceived cost } \\
\text { effectiveness }\end{array}$ & .498 & .176 & 0.357 & 2.836 & .006 & .146 & .850 \\
\hline Perceived risk & .510 & .176 & -0.364 & -2.895 & .005 & .157 & .864 \\
\hline $\begin{array}{l}\text { Adjusted R squared } \\
\text { DW Stat } \\
\text { F Stat }\end{array}$ & $\begin{array}{r}0.35 \\
1.3 \\
18 .\end{array}$ & $\begin{array}{l}9 \\
3 \\
00 * * *\end{array}$ & & & & & \\
\hline
\end{tabular}

As per the results produced in the above table Perceived cost effectiveness and Perceived risk found to have significant impact on the adoption of outsourcing among Sri Lankan Manufacturing and Trading sector. Accordingly the decision makers perception about the cost effectiveness of outsourcing positively impact on the outsourcing decision where as their perception of risk of outsourcing negatively impact on outsourcing decision. These two determinants collectively explains 39\% of the variation in the outsourcing decision in Sri Lankan Manufacturing and Trading sectors.

\section{CONCLUSION}

This study provides rather unique finding with regard to the determinants of outsourcing adoption of Manufacturing /Trading companies in Sri Lanka. One of the significant determinants of outsourcing found as companies perceived cost effectiveness and perceived risk of outsourcing. As the companies realize the cost effectiveness of outsourcing logistic functions compared to do them inhouse, they can minimize unnecessary cost, and make easy, speedy production activities leading to administer a limited number of their resources conveniently.

The cost effectiveness of outsourcing also encourages the companies to make capital funds available for more profitable operations and focus on core competencies of the corporation. However, the findings support evidence for the existence of Number of problems in Logistics related activities when outsourcing. This particular scenario is evidenced with the negative impact of perceived risk has on logistic outsourcing. This provide some indirect evidence of issues in service levels in the outsourcing organization or service provider or the outsourced vendor.

This further confirms that companies fear that important services get neglected by the employees of service provider. Perceived risk has found as the most important determinant of outsourcing logistic functions. Hence the findings of the present study suggests that outsourcing partners should be selected based on their expertise in the operation, their cultural fit with the firm and establishing strategic supplier alliances with outsource vendor, as it may help avoid these problems.

As Beaumont and Sohal (2004) explain outsourcing efforts are not problem-free and prior researchers have identified problems like loss of control, loss of critical skills, outsourcing does not reduce costs as expected, inadequate capabilities of service providers, loss of flexibility and failure to realize the hidden costs generated by the contract.

Hence, entering strong agreements with outsourced vendors considering all possible problems and losses of outsourcing, being more alert on the global outsourcing strategies in order to help or improve the performance can be suggestive. Further, many risks faced by companies must be identified and analyzed from strategic point of view, to get the anticipated benefits from outsourcing.

\section{REFERENCES}

[1] J. Bhagwati, A. Panagariya and T.N. Srinivasan, "The Muddles over Outsourcing," The Journal of Economic Perspectives, Vol.18, No.4, pp. 93-114, 2004.

[2] M.J. Bidwell, "Politics and Firm Boundaries: How Organizational Structure, Group Interests, and Resources Affect Outsourcing,” Organization Science, Vol.23, No.6, pp.1622-1642, 2012.

[3] Central Bank of Sri Lanka/Annual Report 2017

[4] Christine, "Deployment of vendor capabilities and competences throughout the outsourcing process", International Journal of Operations \& Production Management, Vol.32, No.3, pp, 351-374, 2005.

[5] C. Harland, L. Knight, R. Lammin and H.Walker, "Outsourcing: assessing the risks and benefits for organizations", sectors and nations," International Journal of Operations \& Production Management, Vol. 25 No.9.

[6] T. R. Holcomb and M.A.Hitt, "Toward a model of strategic outsourcing,” Journal of Operations Management, Vol.25, pp. 464481. 2007.

[7] R.K. Jain and R. Natarajan, "Factors influencing the outsourcing decisions: A study of the banking sector in India," Strategic Outsourcing: an International Journal, Vol.4.No.3, 2011.

[8] N. Kakabadse and A. Kakabadse, "Critical review - outsourcing: a paradigm shift,” The Journal of Management Development. Vol.19, No. 8, pp. 670-728, 2000. 
[9] G.M. Kenyon and M. Meixell, "Success factors and cost management strategies for logistics outsourcing," Journal of Management and Marketing Research, Vol.7, No.1, 2010.

[10] A.M. Knemeyer, P.R.Murphy, "Evaluating the performance of thirdparty logistics arrangements: a relationship marketing perspective," Journal of Supply Chain Management. Vol.40, No.1, pp.35 - 51, 2004.

[11] T. Kremic, "Outsourcing decision support: A survey of benefits, risks, and decision factors," Supply Chain Management, Vol. 11, No.6, pp. 467-482, 2006.

[12] C. Liyanagamage, "Credit multipliers, uncertainty and the future of the Sri Lankan manufacturing sector, Annual Academic Sessions," Faculty of Humanities and Social Sciences, Open University of Sri Lanka, June 2009.

[13] A. Minondo and G. Rubert, "The effect of outsourcing on the demand for skills in the Spanish manufacturing industry," Applied economic letters, Vol.13, 2006.

[14] Namusonge and Lilian Nanjala Wabwile, "International Journal of Academic Research in Business and Social Sciences,” Vol.5, No.5, pp.190-202, 2015.

[15] B. Nicholas, and S. Amrik, "Outsourcing in Australia," International Journal of Operations \& Production Management, Vol.24, No.7, 2004. 